\title{
Evolution of robotic arms
}

\author{
Michael E. Moran
}

Received: 16 October 2006 / Accepted: 16 November 2006 / Published online: 1 May 2007

(C) Springer London 2007

\begin{abstract}
The foundation of surgical robotics is in the development of the robotic arm. This is a thorough review of the literature on the nature and development of this device with emphasis on surgical applications. We have reviewed the published literature and classified robotic arms by their application: show, industrial application, medical application, etc. There is a definite trend in the manufacture of robotic arms toward more dextrous devices, more degreesof-freedom, and capabilities beyond the human arm. da Vinci designed the first sophisticated robotic arm in 1495 with four degrees-of-freedom and an analog on-board controller supplying power and programmability. von Kemplen's chess-playing automaton left arm was quite sophisticated. Unimate introduced the first industrial robotic arm in 1961, it has subsequently evolved into the PUMA arm. In 1963 the Rancho arm was designed; Minsky's Tentacle arm appeared in 1968, Scheinman's Stanford arm in 1969, and MIT's Silver arm in 1974. Aird became the first cyborg human with a robotic arm in 1993. In 2000 Miguel Nicolalis redefined possible man-machine capacity in his work on cerebral implantation in owl-monkeys directly interfacing with robotic arms both locally and at a distance. The robotic arm is the end-effector of robotic systems and currently is the hallmark feature of the da Vinci Surgical System making its entrance into surgical application. But, despite the potential advantages of this computer-controlled master-slave system, robotic arms have definite limitations. Ongoing work in robotics has many potential solutions to the drawbacks of current robotic surgical systems.
\end{abstract}

M. E. Moran ( $\square)$

Medical and Surgical Specialists,

6101 Pine Ridge Road, Naples, FL 34119, USA

e-mail: memoran2@juno.com

\section{Introduction}

"If you will have the precision out of them, and make their fingers measure degrees like cog-wheels, and their arms strike curves like compasses, you must inhumanize them." (J. Ruskin, The Stones of Venice [1])

Although surgical robotics is in its infancy, the rapid proliferation of surgical systems attests to the fact that this technology is here to stay and that we urologists should brace ourselves for the next wave of technology that will yet again change the way we work [2]. Many in practice are rather startled by the rapid insurgence of this sophisticated technology into the armamentarium of clinical practice. Many are overawed by the sophistication of the equipment that underlies the computer-enhanced technology that lurks "under the hood" of the da Vinci Surgical System (Intuitive Surgical, Sunnyvale, CA, USA). Yet one finds such suppositions are unfounded if one simply looks back on the steady progress leading to our current situation.

This is a historical overview of the history of the prime robotic surgical end-effector, the robotic arm. It is hoped that such an overview will better prepare the urologist to appreciate the pedigree of the sophisticated apparatus we are currently using and, potentially, anticipate the modifications and evolution this technology has for every aspect of urologic surgical practice. History is fascinating in that insights and trends can be used to emphasize ongoing basic research efforts and develop an enlightened opinion of the overall meaning of this technology to us as urologists.

The approach in this historical review will be a bit different from that in other published accounts of robotic technology that is increasingly proliferating [3]. The robotic arm will be the sole topic of this investigation and 
will be dissected rather like the human arm. Some context will be added for literary interest but the focus will be on a sequential timeline of development and how we arrived at a piano-wire based, seven degrees-of-freedom surgical system for urology that is now sweeping across the United States. The attempt is to thoroughly paint a scenario of human aspiration to achieve an augmented, human-like effector that would provide all of the advantages of mechanization and eliminate all of the potential disadvantages of the human actuator. Historical attempts before modern electrical systems will be investigated first. The joints of mechanical systems anthropomorphically reflect the human arm. The shoulder joint of modern mechanical arms will be addressed next. The elbow joint followed by the wrist will then be evaluated. Finally, the hand will be explored in all of the iterations to the present, which in some ways is the bridge from the past to present day surgical systems.

Where will all of this technology end you might ask? This technology, although in its infancy, has a historical legacy that is almost as intriguing as the software and hardware that now underlies these technological wonders. At the conclusion of this article, "cutting edge" basic research that is merging digital technology and robotics with neuroscience and cognitive research in what is often referred to as brain-machine interface systems will be presented. These fusion areas were the ultimate goals of those who began, so long ago, to dream of mechanical systems that would aid and relieve the ardors of labor and augment human performance. Nowhere in medicine is this more necessary than in surgery, where a deftly executed, minimally invasive procedure can alleviate so much pain and suffering [4]. When all is said and done, a well crafted tale can infuse a better understanding of the potential of these enabling technologies than a scientific review of the same. As the saying goes, "Chronology is the last refuge of the feeble minded and the only resort for historians." [5].

\section{da Vinci's robotic arm}

One can think of no finer place to start a historical dissertation on robotics than the master of Renaissance method, Leonardo da Vinci. In the early 1950s, investigators at the University of California scrutinized detailed drawings from da Vinci's notebooks which together form a tome exceeding 1,119 pages dating from 1480 to 1518 and therefore referred to, like the great Atlantic ocean, as the Codex Atlanticus. da Vinci was profoundly influenced by classical Greek thinkers in art and in engineering. Modern investigations increasingly make it clear that he singularly pursued knowledge of everything known to these ancient scholars. $\mathrm{He}$, in effect, was following in the footsteps of such figures as Hero of Alexandria, Philon, and Cstebius who were all reported to be interested in mechanically simulating motion and human attributes. Possibly inspired by quotes from Homer's Iliad, “...since he was working on twenty tripods which were to stand against the wall of his strong-founded dwelling. And he had set golden wheels underneath the base of each one so that of their own motion they could wheel into the immortal gathering, and return to his house: a wonder to look at." (Homer the Iliad, book 18). da Vinci began a systematic method of devising and building the sophisticated mechanical device that was 500 years ahead of its time. His first robotic design was in December 1478, at the age of 26, before he moved to Milan (Fig. 1). In the Codex Atlanticus, folio 812, is a power mechanism that features a front wheel drive, rack-and-pinion automobile. Impressive as it is, it was also fully programmable, with the ability to control its own motion and direction. It is now thought that this "base" would form the basis of his ultimate goal, an fully functional automaton [6].

To animate a humanoid machine he was cognizant of his need to develop a more detailed database of human kinesiology. Leonardo grounded his knowledge further with drafting, anatomy, metal working, tool making, and armor design, in addition to painting and sculpture. Leonardo was
Fig. 1 Leonardo da Vinci's front wheel drive, rack-and-pinion steering animated cart, photos courtesy of Biblioteca

Ambrosiana in Milan
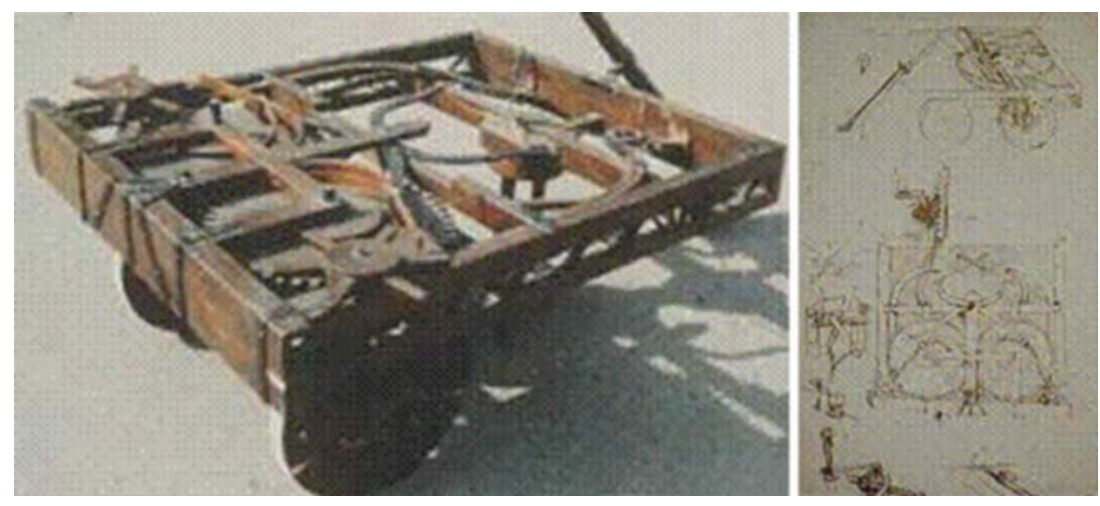
not content with a simple understanding of human anatomy, so he began to investigate and draw comparative anatomy, to better appreciate form and function. "You should make a discourse concerning the hands of each of the animals, in order to show in what way they vary." [7].

In 1495, at about the time he was working on his method of painting on wet plaster and the Last Supper, da Vinci designed and probably built the first of several programmable humanoid robots. From research ongoing at the Florencebased Institute and Museum of the History of Science and work by Rosheim it is now apparent his robot could open and close its anatomically correct jaw, sit up, wave its arms, and move its head [8]. This robot consisted of two independent systems (Fig. 1). The lower extremities had three degrees-offreedom-legs, ankles, knees, and hips. The upper extremities had four degrees-of-freedom-arms with articulated shoulders, elbows, wrists, and hands. The orientation of the arms indicates it could only whole-arm grasp with the joints moving in unison. The device had an "onboard" programmable controller within the chest providing for power and control over the arms. The legs were powered by an external crank arrangement. The Florence-based Institute and Museum of the History of Science has developed sophisticated computer models of this design with streaming video animations. Leonardo probably returned to this design again to impress his erstwhile potential royal patron, Francis I of France. From Lomazzo's writing about Leonardo in 1584, Francesco Melzi (one of his pupils, and heirs) states that Leonardo made several automatons from "birds, of certain material that flew through the air and a lion that could walk...the lion, constructed with marvelous artifice, to walk from its place in a room and then stop, opening its breast which was full of lilies and different flowers." Rosheim believes that the leaf spring-powered cart could have powered the mechanical lion and his automaton knight. Leonardo's multi-degrees-offreedom automaton is an appropriate starting point for man's technical interest in recapitulating form and function. da Vinci's intense attention to detail will be a recurrent theme throughout this historical sojourn. In Leonardo's own words, "With what words, O Writer, will you describe with like perfection the entire configuration which the drawing here does?" (da Vinci, 1513).

\section{From automata to the Industrial Revolution}

It has been suggested that the son of a glove-maker might well have been the spark that ignited the Industrial Revolution [9]. Jacques de Vaucanson was a gifted mechanical designer and builder of some of the most complex, clockwork automata throughout the eighteenth century. He was born in Grenoble in 1709 the youngest of ten children and began to show signs of his mechanical genius at a young age. Vaucanson too showed marked interest in the functioning of the human body, and is known to have attended classes in anatomy and medicine at the Jardin du Roi; he probably came into contact with Claude-Nicolas Le Cat (famed lithotomist). By 1738, the young entrepreneur had designed and built an automaton flute player, which was called an "androide". By 1739 he had added two other automata to his exhibition, a pipe-and-drum player and a mechanical duck. The most popular and famous, by far, of all of his mechanical contrivances, was the duck [10]. Our interests here are mechanical arms, so attention to the duck and drummer will fade and we shall remain focused upon the flutist (Fig. 2). The price for admission to Vaucanson's rented hall was significant, approximately three livres (one week's salary in those days). The Abbe Desfontaines, who was agape about the human-like characteristics of the flutist describes the insides as containing an "infinity of wires and steel chains...form the movement of the fingers, in the same way as in living man, by the dilation and contraction of muscles." Vaucanson gave a detail account of his android to the Academy of Sciences and, in fact, published and illustrated account [11].

Others followed in Vaucanson's wake. Most significant were the Swiss clock-making family named Jaquet-Droz. In 1774, the father, Pierre, with his son Henri-Louis, began to execute three life-sized automata with particular emphasis on their human-like capabilities. It is likely that the village surgeon helped with the development of the arms and hands of these androids. These craftsmen made every attempt to simulate a real human's anatomy. They created an artist, a writer, and a musician. The musician played a clavichord by applying pressure to the keys with her fingertips (Fig. 3).
Fig. 2 de Vaucanson's flute player, details of the finger mechanism are included

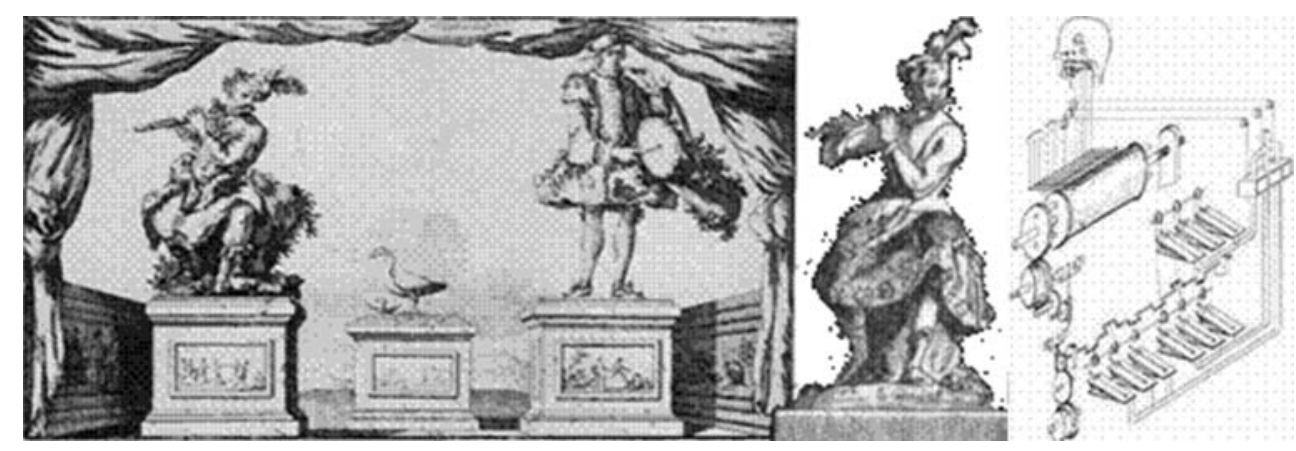



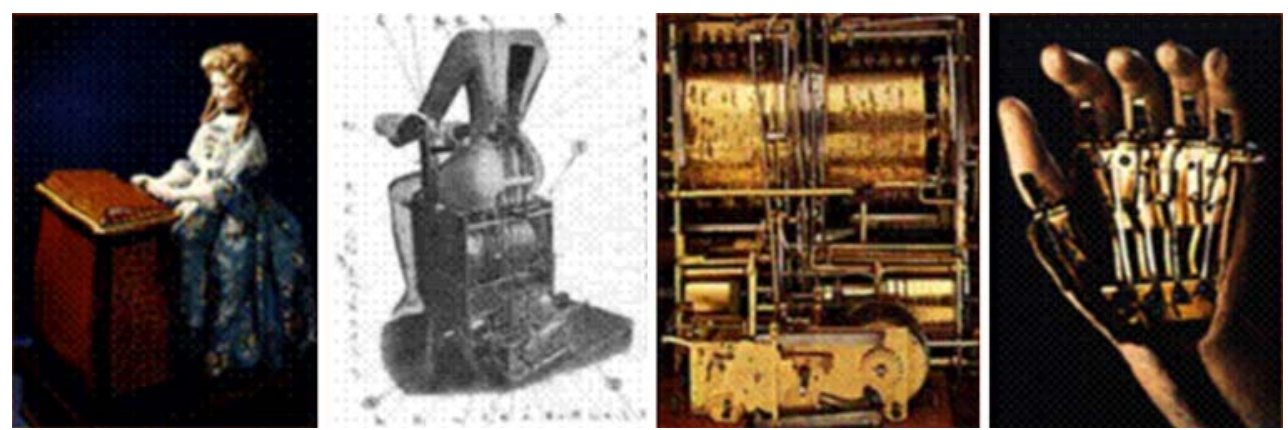

Fig. 3 Jaquet-Droz's 1774 lady musician, reproduced with permission [12]

The final automaton of interest in this series is Wolfgang von Kempelen's chess player, often called the Turk [13]. It was constructed in 1769 for the Empress Maria Therese. The Turk was an elaborate hoax with a human operator concealed inside the complex cabinetry underneath the chessboard. The automaton though, had an ingenious system of mechanisms that automated the chess player's left arm and hand. The chess player was a carved-wood figure that sat behind a wooden chest dressed in Turkish garb. The head moved on his neck, the eyes moved in their sockets, but the left arm and hand were magnificently orchestrated. The Turk engendered a wide variety of writings about the possibility of animating human reason and human activities. The mechanics of the arm were controlled by the "director", the name given by those who knew that the games were human-controlled. Kempelen had designed a pantograph, a device that enabled the director to steer the automaton's left arm from inside of the chest (Fig. 4). The limb would first be raised, then the hand would center over the desired chess piece to be moved. The arm would lower towards the piece and a collar would be turned to allow the end of a lever in his hand make the Turk's fingers grasp the chess piece. The automaton's fingers were wooden and during a match, the hand was placed inside a glove so it could grasp the chess pieces with more agility. Each finger had its own series of cables connected to the director's pantograph.

\section{Robots of the World's Fair}

It is possible that in the recent history of the world only wars have had a more dramatic impact upon our society than expositions. The first industrial exposition occurred in Paris in 1798 and enabled the public to witness progress and technology that could change the lives of everyone. This process continued into the nineteenth century when the extraordinary potential of remote-controlled robotic devices was clearly demonstrated to an unsuspecting public at the 1898 Electrical Exhibition in Madison Square Garden, New York City. Nicola Tesla was at the height of his inventive prowess when he brought upon the unprepared world, a fully automated, remote-controlled robotic submersible boat (Fig. 5). "Teleautomata will ultimately be produced, capable of acting as if possessed of their own intelligence, and their advent will create a revolution." (Tesla, 1898 [14]).

It would be 37 years and one World War later, at the San Diego Exposition, that the next robotic device would greet the public. A little known and not widely regarded 2,000-lb mechanical man was demonstrated by its inventor, Professor Harry May. Alpha, the robot's name, was $6^{\prime} 2^{\prime \prime}$ tall and could roll its eyes, open and close its mouth, sit and stand, move its arms, and fire a revolver (Fig. 6). In 1939, the super secret and far more popular mechanical man was
Fig. 4 von Kempelen's Turk, chess player with illustrated left arm mechanisms

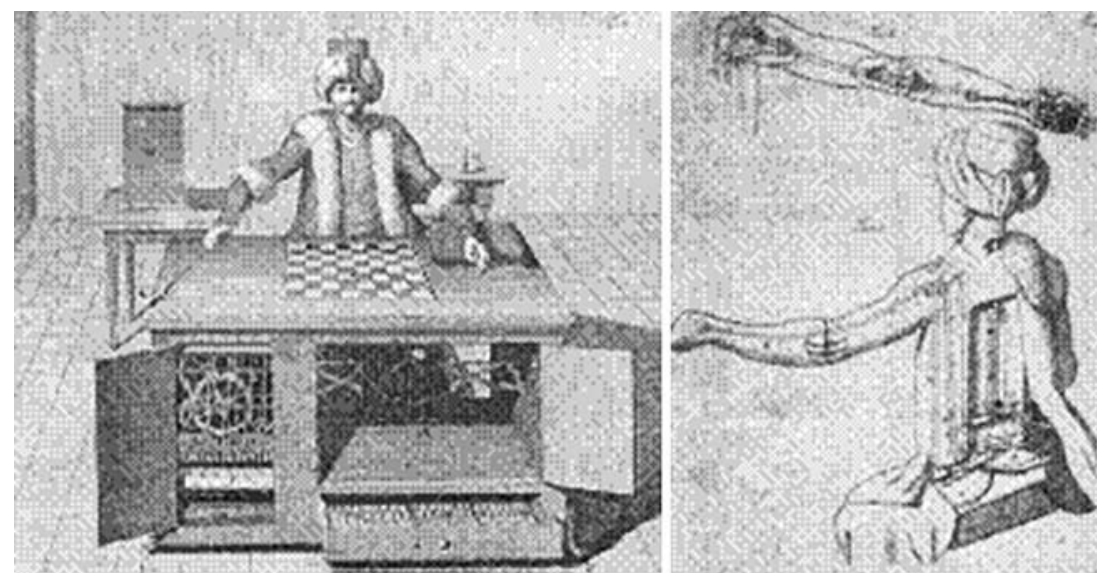



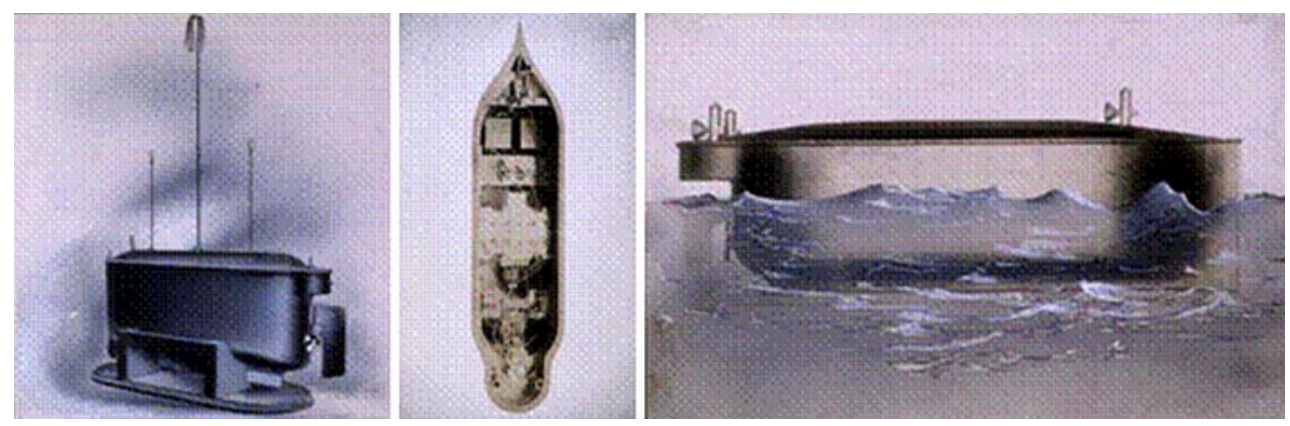

Fig. 5 Nicola Tesla's 1898 remote controlled robotic vessel
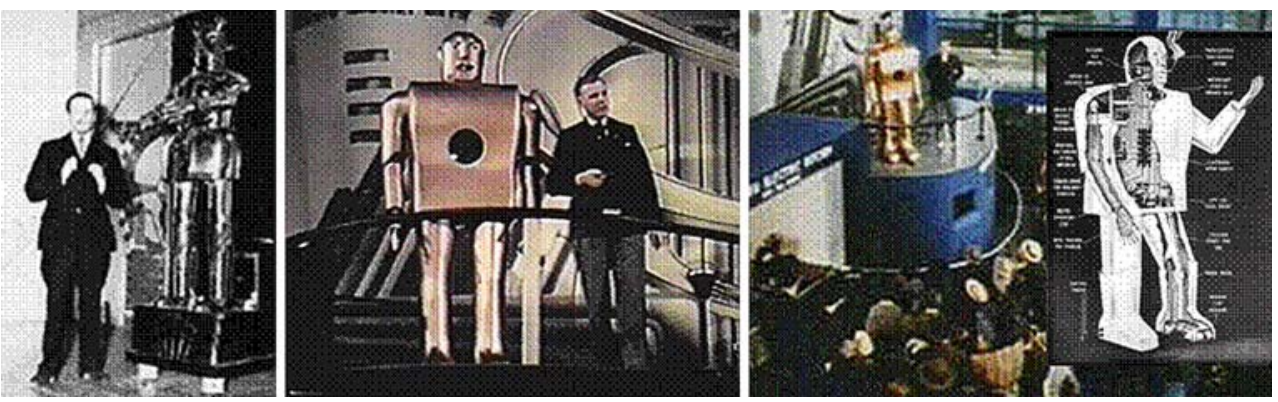

Fig. 6 The World's Fair robots: far left, Harry May's Alpha; right, three Westinghouse Elektro robots

introduced at the New York World's Fair by the electronics giant, Westinghouse. Elektro was a spectacular hit at the Westinghouse Pavilion. Elektro would stand high above the audience on a platform and, supposedly, respond to English spoken commands (Fig. 6). Elektro was able to perform far more complex tasks than Alpha, he was able to move about on the stage with a strange sliding gait. Elektro was approximately 7 feet in height and cost the Westinghouse Corporation several hundred thousand dollars to make in Mansfield, Ohio [15]. Records of the company show they manufactured eight robots from 1931 to 1940 . These robots could all move actuated arms and walk. Elektro used a 78rpm record player to simulate conversation and had a vocabulary of more than 700 words. Elektro was captivating, he enthralled millions of visitors and went on tour after the World's Fair and even appeared in a bad "B" movie, "Sex Kittens Go to College", subtitled Beauty and the Robot. Most curious of all, these mechanical men were not called robots because Carel Kapek's play, "Rossum's
Universal Robots" had not achieved the notoriety and cultural conversion of this word at this time.

The electronics in these early metal men were primitive, with loud electrical motor drivers and vacuum tube relays. They would be replaced with microcircuits and far more rapid, efficient, and quiet mechanics in the not too distant future. The World's Fair phenomenon and robots continues to this day. The Worlds Expo 2005 was held in Aichi, Japan and closed in September with over 22,000,000 in attendance. The theme was "Nature's Wisdom," but the technology was definitely center stage. The robot assumed a key role with "we live in a robot age". Working robots roved around the grounds and performed routine chores including sanitation, garbage collection, security, guide robots, childcare duties, and handicapped aid robots (Fig. 7). Multiple prototype robots were demonstrated for 11 days in June. The exhibition also had a "Robot Station" where visitors were able to interact with a whole host of robot-based venues. As is true of most such industrial expositions,

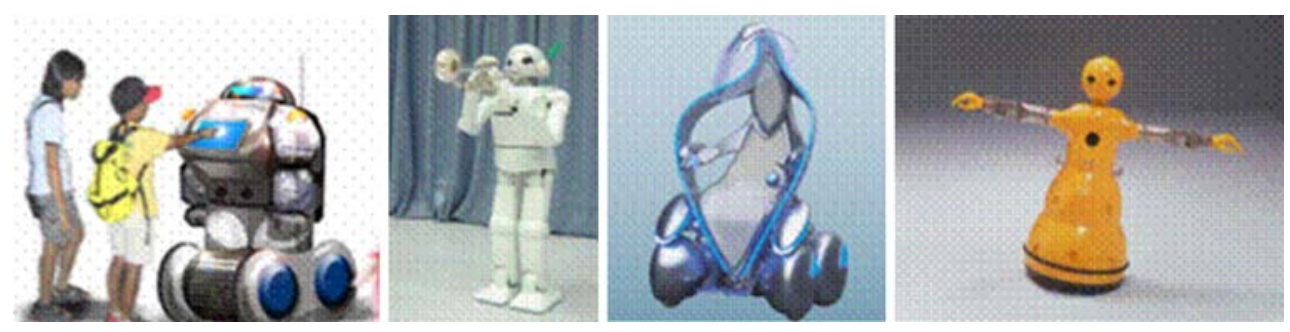

Fig. 7 Expo 2005 Aichi, Japan with increasingly sophisticated robots, and robot actuators (look at the arms) 
manufacturers, including Toyota, Mitsubishi, and Brother Industries, were present to show-off their future technology [16].

\section{Early modern robots and robotic arms}

Now, with the advent of electronics and the incorporation of solid-state transistors instead of vacuum tubes, the evolution of the microcircuit and more rapid computer systems, the stage was set for early modern robotic arm evolution. The first "position controlling apparatus" was patented in 1938 by Willard Pollard (Fig. 8). This was a spray finishing robotic arm that had five degrees-of-freedom and an electrical control system. Although Pollard [17] never built his arm, his design and interest in an industrial application for automated robotic arms would spur on the ingenuity of others. Harold A. Roselund [18], working for De Vilbiss, developed another sprayer that was indeed manufactured. Both arms were very sophisticated for their time, and each solved movement at the respective joints in unique ways; the electronic controller systems lacked the fidelity required to make them broadly utilizable, however. The modern era of robotics was launched by the intrepid use of these two, little known arms developed in the late 1930s.

Unimate introduced its first robotic arm in 1962 (Fig. 8) [19]. The arm was invented by George Devol and marketed by Joseph Engelberger. The first industrial arm was installed at the General Motors plant in Ternstedt, New
Jersey, for automated diecasting. Ultimately, approximately 8,500 units were sold. Industrial robots graduated from the laboratory to the factory [20]. It is interesting that in this process the robotic arm's movements and the degrees-offreedom incorporated nautical terms for robotics-pitch, yaw, and roll.

Engelberger developed the first robotics company, called Unimation (from Devol's Universal Automation robot), to sell their two-ton robotic arm, the Unimate. Unimation eventually sold 8,500 Unimates. Kawasaki bought the license to manufacture industrial robot arms from Unimation in 1966. Competition came quickly, the Cincinnati-based Milacron appeared, and by 1963 AMF Hermatool brought out their commercially available Versatran industrial robot which Japan imported in 1967. A whole host of academic centers became interested in the applications of microelectronics and the potential for these robotic arms (Fig. 9). A Stanford Research Institute investigator, Victor Scheinman, began working on electrically powered articulated arms that could move through six axes, which he called the Stanford arm. More complex tasks could now be given to the robotic arms. Marvin Minsky, then from MIT, built a robotic arm for the office of Naval Research, for possible underwater exploration. Twelve single-degree-of-freedom joints were used to actuate this electro-hydraulic high-dexterity arm. Scheinman continued his work on robotic arms and, with backing from General Motors, Unimation developed Scheinman's technology into a Programmable Universal Machine for Assembly (PUMA).
Fig. 8 Early modern robotic arms: left, the Pollard painting arm; right, Unimate
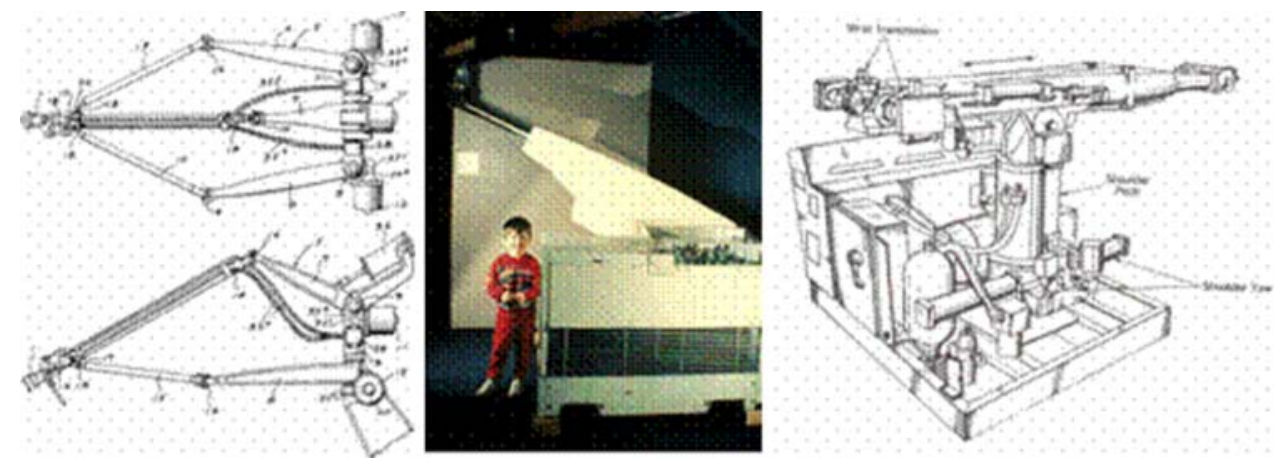
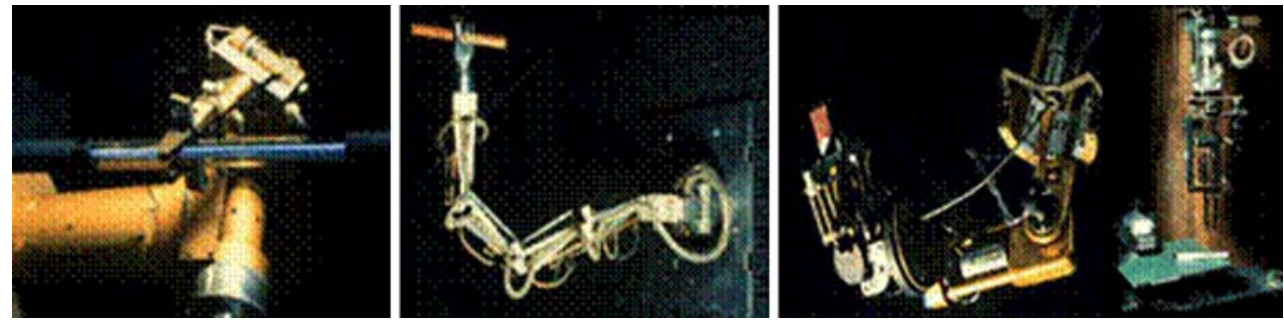

Fig. 9 From left to right, Rancho Arm, 1963; Minsky’s Tentacle Arm, 1968; the Stanford Arm, 1969; Silver Arm, 1974 


\section{The robotic arm}

So we come to the robotic arm itself and applications to the medical field in particular. The most obvious method in this evolution was adaptation along the lines of human anatomy and kinesiology (Fig. 10).

\section{Shoulder joint}

The shoulder joint is the highest load-bearing joint in the arm. The three degrees-of-freedom at the shoulder are pitch, yaw, and roll. The shoulder has the widest range of motion of any joint in the human body and is the foundation for most modern robotic arms. The horizontal flexion and extension (yaw) of the human shoulder is $160^{\circ}$. The forward flexion and hyperextension of the shoulder (pitch) is $240^{\circ}$. Finally, the medial and lateral rotation (roll) is $160^{\circ}$. In the normal human, the pitch and yaw are perpendicular to the arm, whereas the roll is in-line with the arm.

\section{Elbow joint}

The elbow joint provides extension, retraction, reacharound, and angular reorientation of the wrist and hand. Classically, the elbow provides $150^{\circ}$ of pitch. Many types of mechanical elbow joint have been used in robotic arm manufacture. These include telescoping, revolute (subdivided by drive-train), intermediate, remote, and direct. Of these mechanical types, the revolute is most similar to the human arm. The telescoping was an early type of robotic arm joint, it deviates much from the human anatomic concept and applications have been limited.

\section{Wrist joint}

The wrist mechanisms developed for robotic arms were crucial in even the earliest prototypes (Fig. 9). The wrist is

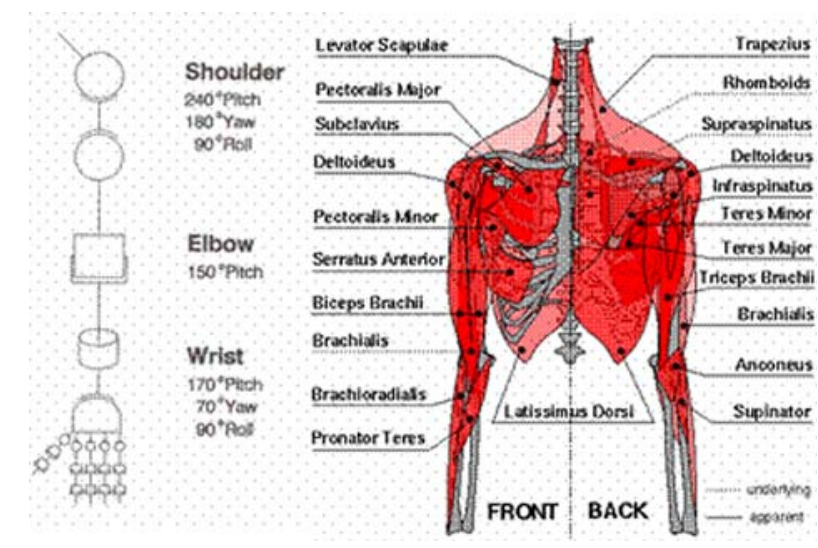

Fig. 10 Degrees-of-freedom in the robotic arm and the musculoskeletal system of the human equivalent the end-effector terminus of the robotic arm and it allows the arm to be manipulated in three-dimensional space. Without a wrist, the mechanical arm would function more like Leonardo's robot or some most modern crane arms. This joint is becoming increasingly complex in modern robots and is one of the fundamental features on the da Vinci Operating System. The robotic wrist is the sine qua non for high-performance robotic arms. If the human wrist moves $45^{\circ}$ off center, ability to roll degenerates, resulting in gimbal locking. The earliest robotic applications of wrists were in the very first painting and welding robotic arms. Much more sophisticated wrists enable more dexterous teleoperated systems, but singularity problems are still a problem, and almost everyone who has used the da Vinci Surgical System has probably experienced gimbal locking of the wrist.

\section{Hand}

The hand is a "differentiated" end-effector of the robotic arm that defines the purpose and the capacity of the arm. The hand is a multi-tasking tool capable of diverse functions, for example grasping, manipulating, and pushing. A robotic hand has multiple control issues, both motor and sensory perception. Many universities are currently investigating this topic, more so than in industry.

\section{Discussion}

The five principal types of robotic arm are: rectangular coordinate, polar coordinate, cylindrical coordinate, revolute coordinate, and self compliant automatic robot assembly (SCARA). Two more recent additions are called serpentine and anthropomorphic [21]. These arms can be subdivided by the types and complexity of each of their joints and control systems. The evolution of robotic arms is rapidly developing, however, and such schemes probably do more for organizing information than in defining the actual product. Applications to medicine, and surgery in particular, are ripe for companies, because classic fields of application, for example nuclear reactor work, have declined. In the past 40 years radical improvements have been made and more degrees-of-freedom are now possible. Downsizing and cost reduction will follow. Hand technologies will rapidly advance as computer-control issues improve and work at universities will find fruitful applications in industry and medicine. "Haptics" and other sensory systems will be added to advanced surgical robotics as this technology evolves.

It is necessary to discuss the two additional categories of robotic arm a bit further, because they may become more important to medical applications. The first is the 
serpentine robots. These devices were originally designed on the basis of the kinesiology of another complex biological joint, the spine (Fig. 11). The purpose of making serpentine robots was to produce a device with more degreesof-freedom than the normal human arm. As computercontrol algorithms advance and the means to control the complex maneuvers of $>10-20$ or 30 degrees-of-freedom become available, these systems have become increasingly complex. The first such systems were called "serpentine" because it was necessary for the robotic arms to "snake" through passages and pipes to inspect nuclear reactors, fuel tank baffles, and wing spars. To overcome the multiple-joint-control issues and prevent restrictive backlash, Miyake in 1986 described innovative solutions in control [22]. In 1968 the US Navy funded a spine-like arm for ocean exploration; this has been called the Scripps tensor arm. Another such ultrahigh-dexterity robotic arm, called the Articulating Mechanism, was developed by Ralph Mosher in 1969. It was a modular and low-cost alternative to the Scripps design, but was not as precise. Many of the space arms used on the United States Space Shuttle were serpentine. The arm designed by Frederick Wells in 1970 at the Marshall Space Flight Center in Huntsville, Alabama, was such a device. This arm has continued to evolve with improvements by Iwatsuka, in 1986, and by Wuenecher. Wuenecher called his device the remote control manipulator intended to aid astronauts. The Spine Robot is a Swedish-made serpentine robotic arm

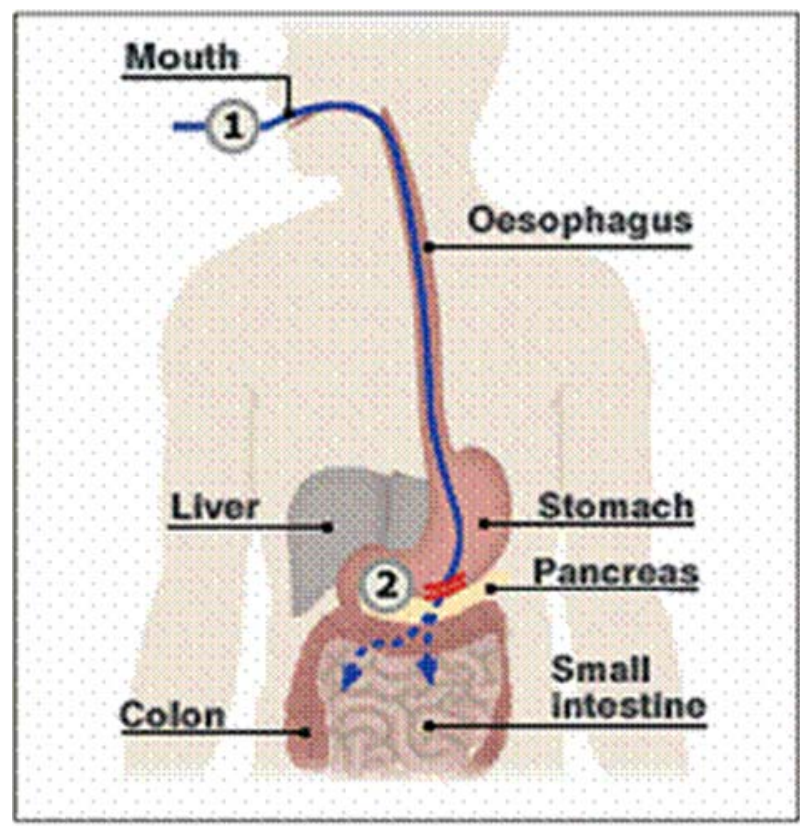

1. The endoscope with incision toots

2. The stomach watt is cet to access the abdominat c wity

Fig. 11 Serpentine robotic arm with future potential for "woundless" surgery invented by Ove Larson and Charles Davidson in 1983. It consists of stacked ovoidal discs controlled by opposable cables. There are now many versions of this design which use bellows, U-joints, and pressurized capillary systems (Scheinman). In 1984, Motohiko Kuura designed expandable and contractible arms for serpentine applications. The final addition in this series is the 1991 modular robotic joint (MJR) arm invented by Mark Rosheim [21]. The advantages of this system are that it has more degrees-offreedom than the human arm, increases modularity, and is fault tolerant, if one joint fails another is capable of providing the mobility needed to accomplish its task. Why would surgeons be at all interested in more degrees-offreedom, you might wonder? Another coming technological tour-de-force is woundless surgery. This type of complex surgery is also called peroral, transgastric endoscopic surgery, and cholecystectomies, appendectomies, and tubal bandings have already been performed [23, 24]. To achieve more complex tasks, for example nephrectomy or radical prostatectomy, an ultrahigh-dexterity robotic arm will be necessary.

Another aspect of ongoing work is funded by grants supporting the rehabilitation of handicapped individuals [25]. Neuro-enhanced prosthetics such as cochlear implants, retinal implants, and highly dexterous limb prosthetics are already available [26]. Direct neural control would produce hybrid devices with the reliability and control of robotic arms and a completely natural interface via the individual's own neocortex. Patients with "locked in syndromes", for example severe disabling cerebral vascular accidents or severe amyelotrophic lateral sclerosis (ALS), have already been implanted with new intracranial electrodes that can directly interact with computers [27]. Fusion technology threatens the way we think about our own humanity, perhaps our own neural plasticity will enable advanced control directly by use of our own thought (Fig. 12) [28].

Some believe invasive implantable arrays are the future mode of choice which will enable our neocortex to link directly to the computers and mechanical actuators that will enable precision control. Others, however, believe this can be accomplished without surgically implantable arrays, and that the EEG has the potential to be a brain-machine interface [30].

The robotic arm is finally becoming the tool envisaged by those workers whose legacy started this intellectual exercise. The robotic surgical system we currently use in Urology is the "tip of the iceberg" for robotic systems [31]. Although seemingly sprung on unsuspecting clinicians, these complex machines represent a long lineage of work beginning from early modern times and continuing to the present. Whether or not you believe this currently expensive technology will affect your practice, whether you 
Fig. 12 Amputee with neuralinteractive robotic prosthesis. Center is Kennedy's implantable neural array for patients with "locked-in syndrome." Right is the concept from Miguel Nicolelis' laboratory at Duke University showing learned cortical control in old work monkeys for controlling a robotic arm both directly and remotely from Durham, N.C. to MIT in Boston [29]

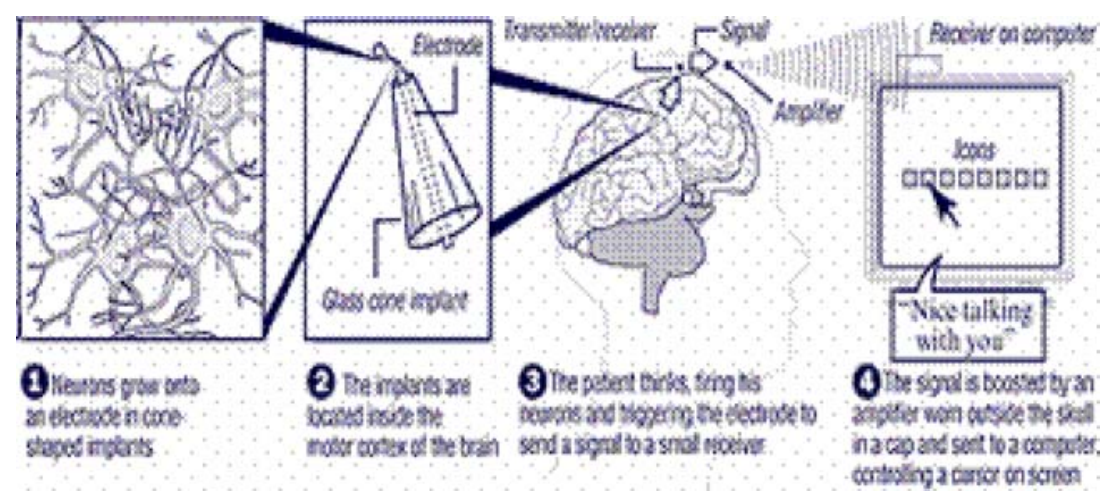

believe you can do better yourself laparoscopically or via open surgical methods, and whether or not you believe the technology is moving faster than human social systems can handle it, there is no longer any doubt this is just the first of many potential incursions of the robotic arm into the surgical arena of the future. The robotic arm has an absolutely fascinating history of which this is just a brief glimpse.

\section{References}

1. Ruskin J (1995) Selected writings. JM Dent-Everyman, London

2. Moran ME (2003) Robotic surgery: urologic implications. J Endourol 17(9):695-708

3. Cepolina F, Challacombe B, Michelini RC (2005) Trends in robotic surgery. J Endourol 19(8):940-951

4. Birkett DH (2002) Robotics. Surg Endosc 16:1257-1258

5. Ellis JJ (2000) Founding brothers: the revolutionary generation. Vintage Books, New York, $p 18$

6. Rosheim ME: Leonardo's programmable automaton. A reconstruction. http://www.anthrobot.com/press/article_leo_programmable.html

7. Nuland SB (2000) Leonardo da Vinci. Penguin Books, New York

8. Capello S, Moran ME, Belarmino J, Firoozi F, Kolios E, Perrotti M (2005) The da Vinci robot. 23rd world congress on endourology. J Endourol 19(1):A133

9. Wood G (2002) Edison's eve. A magical history of the quest for mechanical life. Anchor Books, New York

10. Riskin J (2003) The defecating duck or, the ambiguous origins of artificial life. Critic Inq 29(4):599-633

11. Vaucanson J (1738) Le Mechanisme du fluteur automate. J. Guerin, Paris

12. Chapuis A, Droz E (1958) Automata: a historical and technical study. Trans Alec Reid, New York

13. Standage T (2002) The turk. The life and times of the famous eighteenth-century chess-playing machine. Berkeley Books, New York

14. Belarmino J, Moran ME, Firoozi F, Capello S, Kolios E, Perrotti M (2005) Tesla's robot and the dawn of the current era. Society of urology and engineering. J Endourol 19(7):A214, 915
15. Szondy D: http://www.davidszondy.com/future/robot/elektro1.htm

16. Belarmino J, Moran ME, Firoozi F, Capello S, Kolios E, Perrotti M (2005) An oriental culture of robotics-the coming maelstrom. Society of Urology and Engineering. J Endourol 19(7):A119, 906907

17. Pollard W (1942) U.S. Patent 2,286,571. "Position controlling apparatus." Filed 22 April 1938 and issued 16 June 1942

18. Roselund H (1944) US Patent 4,344,108. "Means for moving spray guns or other devices through predetermined paths." Filed 17 August 1939 and issued 14 March 1944

19. Devol G (1961) US Patent 2,988,237. "Programmed article transfer." Filed December 10,1954 and issued June 13, 1961

20. Engelberger J (1989) Robots in service. MIT Press, Cambridge

21. Rosheim ME (1994) Robot evolution. The development of anthrobotics. Wiley, New York

22. Miyake N (1986) US Patent 4,568,311. "Flexible wrist mechanism." Filed 11 January 1983 and issued 4 February 1986

23. Hochberger J, Lamade W (2005) Transgastric surgery in the abdomen: the dawn of a new era? Gastrointest Endosc 62(2):293-296

24. Park PO, Bergstrom M, Ikeda K, Fritscher-Ravens A, Swain P (2005) Experimental studies of transgastric gallbladder surgery: cholecystectomy and cholecystographic anastomosis. Gastrointest Endosc 61(4):601-606

25. Warwick K (1997) March of the machines. The breakthrough in artificial intelligence. University of Illinois Press, Urbana

26. Clark A (2003) Natural-born cyborgs. Oxford University Press, Oxford

27. Perkowitz S (2004) Digital people. From bionic humans to androids. Joseph Henry Press, Washington

28. Moravec H (1999) Robot. Mere machine to transcendent mind. Oxford University Press, Oxford

29. Nicolelis MAL, Chapin JK (2002) Controlling robots with the mind. Sci Am 287(4):46-53

30. Millan JR, Renkens F, Mourino J, Gerstner W (2004) Noninvasive brain-actuated control of a mobile robot by human EEG. IEEE Trans Biomed Eng 51(6):1026-1033

31. Diodata Jr MD, Prasad SM, Klingensmith ME, Damiano Jr RJ (2004) Robotics in surgery. Current Prob in Surg 41(9):748-810 